\title{
Teeth Consultant
}

\section{Paul Wilkins*}

Public Relations and Communications, UK

*Corresponding author: Paul Wilkins, UK

Submission: 酱 September 27, 2017; Published: 酱 November 29, 2017

\section{Opinion}

While you may have seen the point I've given, clearly, a few times about the Unnatural/Unexplict word 'Doctor' staying more stuck on people's minds making health problems thought of more therefore suffered more, and the need for it to be changed to a much more Natural/Explicit title which staying a lot less stuck on people's minds would make health problems thought of a lot less therefore suffered a lot less; I now have another similar point to make.
Especially for people having lots of trouble with their teeth/jaw could it prove helpful in getting this off their mind to some extent by changing the Unnatural/Unexplicit word 'Dentist' to a much more Natural/Explicit title such as 'Teeth Consultant' which staying less stuck on people's minds would result in trouble with their teeth/ jaw noticed a lot less.

This is no-where near as important as the word 'Doctor' being changed but maybe something at a later no rush date to be considered. 